\title{
Proximal Tibiofibular Syndesmosis Injury in a Professional Football Player: Case Report
}

\section{Profesyonel Futbolcuda Proksimal Tibiofibular Sindesmoz Yaralanmasi: Olgu Sunumu}

\author{
Nevzad Denerel ${ }^{1}$, Erdem Kaan ${ }^{2}$ \\ ${ }^{1}$ Sports Medicine Department, Dr. Burhan Nalbantoğlu State Hospital, Turkish Republic of Northern Cyprus \\ ${ }^{2}$ Orthopaedics and Traumatology Department, Silivri State Hospital, İstanbul, Turkey
}

N. Denerel

0000-0002-2760-7035

E. Kaan (iD

0000-0002-4213-1848

Geliş Tarihi / Date Received: 15.01.2018

Kabul Tarihi / Date Accepted: 21.02.2018

Yayın Tarihi / Published Online: 19.05.2018

\section{Yazışma Adresi /}

Corresponding Author:

Nevzad Denerel

Dr. Burhan Nalbantoğlu Devlet Hastanesi, Spor Hekimliği, Lefkoşa, Turkish Republic of Northern Cyprus

E-mail: nevzaddenerel@gmail.com

\section{ABSTRACT}

Tibiofibular syndesmosis is defined as a fibrous complex of the intraosseous membrane, the anterior and posterior tibiofibular ligaments connecting tibia and fibula to each other. Proximal tibiofibular syndesmosis injuries, especially without tibiofibular dislocation are very rarely seen in the literature. In this paper, the case of a professional football player with proximal tibiofibular syndesmosis injury is presented. He was a 26 year old football player who could not resume the game after an opponent's tackle. On examination, meniscal and ligamentous tests were normal, but edema, pain with palpation and (+) tinel sign with percussion of the fibular head were obtained. Additionally, increase in mobility of the fibular head was observed. After all radiological tests, the patient was diagnosed with "Proximal Tibiofibular Syndesmosis Sprain Grade-II", and a return to play period of 4-6 weeks was predicted. The player started to train with the team following the 30 days long rehabilitation protocol. There is no specific information about clinical and radiological signs to explain proximal tibiofibular joint (PTFJ) injuries in textbooks of orthopedics and sports medicine. Therefore, PTFJ injuries can be missed or misdiagnosed due to lack of information and experience. Our case is one of the two cases in the literature with no dislocation of PTFJ. Studies with larger series will help physicians to cover the lack of information and experience about proximal syndesmosis injuries. Moreover, it will help obtaining the right treatment protocol, and receiving a more effective answer without delay.

Keywords: Football injuries, lateral knee pain, proximal tibiofibular joint, proximal syndesmosis injury

\section{öz}

Tibia ve fibulayı birbirine bağlayan; interosseöz membran ile anterior ve posterior tibiofibular bağlardan oluşan fibröz yapı "tibiofibular sindesmoz" olarak adlandırılır. Literatürde tibiofibular dislokasyon olmaksızın proksimal tibiofibular sindesmoz bağ yaralanmasının oldukça ender rastlanan bir durum olduğu görülmektedir. Bu olgu sunumunda, Türkiye Süper Liginde mücadele eden bir profesyonel futbolcuda meydana gelmiş proksimal tibiofibular sindesmoz yaralanması tartışılacaktır. Olgu 26 yaşında ve erkekti; maç sırasında rakibinin müdahalesi sonrası oyuna devam edememişti. Fizik muayenesinde, menisküs ve bağ testleri normal olmakla birlikte; fibula başı düzeyinde ödem, palpasyonla ağrı ve perküsyon ile tinel bulgusu saptandı. Ayrıca fibula başının mobilitesinde artış gözlendi. Fizik muayene ve radyolojik görüntüleme tetkikleri sonucunda, sporcuya "Proksimal Sindesmoz Sprain Evre-2" tanısı konuldu ve 46 hafta iyileşme süresi öngörüldü. Sporcunun rehabilitasyon süreci sonrası 30 gün içinde takımla birlikte çalışmalara katılması 
planlandı. Klasik ortopedi ve spor hekimliği ders kitaplarında proksimal tibiofibular eklem (PTFE) yaralanmalarını açıklayacak spesifik klinik test ve radyolojik belirtilere ilişkin bilgi olmadığı görülmektedir. Bu nedenle oldukça ender rastlanan PTFE yaralanmaları, bilgi ve deneyim eksikliği ile birleşince sıklıkla gözden kaçabilmektedir. Proksimal sindesmoz yaralanması ise daha da seyrek görülmekte ve bu nedenle klinik olarak şüphe duyulmadığı için tanı ve tedavide zorluklar yaşanmaktadır. Literatürde PTFE yaralanmaları incelendiğinde, bu olgu dislokasyon olmaksızın sindesmoz yaralanmasına değinen iki olgudan biri olarak öne çıkmaktadır. Sonuç olarak; proksimal sindesmoz yaralanmasına ilişkin daha geniş serilerle yapılacak çalışmalar, hekimlerin bilgi ve deneyim eksikliğinin giderilmesine yardımcı olacak, ayrıca tedavide izlenecek yolun belirlenmesini ve daha kısa sürede, daha efektif yanıt alınmasına aracı olacaktır.

Anahtar Sözcükler: Futbol yaralanması, lateral diz ağrısı, proksimal tibiofibular eklem, proksimal sindesmoz yaralanması

Available at: http://journalofsportsmedicine.org and http://dx.doi.org/10.5152/tjsm.2018.101

Cite this article as: Denerel N, Kaan E. Proximal tibiofibular syndesmosis injury in a professional football player: case report. Turk J Sports Med. 2018;53(3):131-5.

\section{Gíiș}

Proksimal tibiofibular eklem kompleksi, proksimal tibiofibular eklem ve tibiofibular sindesmozdan oluşur. Proksimal tibiofibular eklem, lateral tibial kondil ve fibula başı arasında oluşan sinovyal bir eklemleşmedir. Tibiofibular sindesmoz ise tibia ve fibulayı birbirine bağlayan, interosseöz membran ile anterior ve posterior tibiofibular bağlardan oluşan fibröz yapıdır. PTFE; kemik yapılara, muskuloligamentöz komplekse ve korunaklı pozisyonuna bağlı olarak doğal stabil bir eklemdir (1). Eklemin majör stabilizatörleri arasında, eklem kapsülünü kalınlaştırarak stabiliteye katkı sağlayan anterosuperior ve posterosuperior tibiofibular bağlar sayllabilir. Ek olarak, lateral kollateral bağ, biseps femoris tendonu, popliteus tendonu, arkuat ligaman da eklem stabilitesine katkı yapan elemanlardır (2). Proksimal tibiofibular eklemin inklinasyonu ve formu açısından anatomik varyasyonları da belirlenmiştir (3).

Eklemin lokalizasyonu ve doğası nedeniyle proksimal tibiofibular eklem veya sindesmoz yaralanmaları oldukça nadir rastlanan yaralanmalardır. Dolayısıyla ilk karşılaşıldığında tanı ve tedaviye ilișkin çeșitli zorluklar olabilmekte ve bu durum iş gücü kayıplarına yol açmaktadır. Özellikle buradaki gibi profesyonel sporcular söz konusuysa ortaya çıkan tablo daha ciddi olabilmektedir. Sindesmoz yaralanması denildiğinde genellikle, ayak bileği inversiyon torsiyonu sonrası meydana gelen üst ayak bileği yaralanmaları akla gelir. Literatür incelendiğinde tibiofibular dislokasyon olmaksızın proksimal tibiofibular eklem ve sindesmoz bağ yaralanmasına oldukça ender rastlandığı ortaya çıkmaktadır. Burada, bir Türkiye Süper Ligi profesyonel futbolcusunda meydana gelmiş olan proksimal tibiofibular sindesmoz yaralanması sunulmaktadır.

Proksimal tibiofibular sindesmoz yaralanmaları klinik olarak genellikle tibiofibular eklem ve proksimal fibula çevresinde şişlik ve hassasiyet ile kendini gösterir. Ayrıca hastalar, dizlerinin eklem içinden çıkacağı hissi ile gelebilirler (4). $\mathrm{Bu}$ yaralanmalarda ilk etapta çekilen direkt radyografiler çok yararlıdır. Direkt grafilerde fibula başının laterale doğru yer değiştirmesi gözlenir ve eklem aralığında bir genişleme de söz konusudur. Sağlam taraf grafilerinin de istenmesi karşılaştırma ve tanı konması açısından yararlı olacaktır. Yarar sağlayacak tetkiklerden biri de elektromiyografi (EMG)'dir. EMG'nin yapılması peroneal sinir hasarının saptanması açısından anlamlıdır ve pozitif bulgu durumunda tedavinin yönü değișecektir. Literatürde EMG bu tip yaralanmalarda rutin olarak istenmemektedir.

\section{OLGU}

Yirmi altı yaşında, $184 \mathrm{~cm}$ boyunda ve $81.2 \mathrm{~kg}$ ağırlığında olan erkek futbol oyuncusu, Türkiye Süper Lig maçı sırasında rakibinin kayarak sol dizine anterolateralden yaptığı kontakt müdahale sonucunda sol ayağı çimde sabit iken dizi hiperekstansiyona gitmiş ve oyuna devam edememişti. İlk muayenede sol diz diş tarafta lokalize ağrı belirlendi. Akut tedavi olarak saat başı $15 \mathrm{dk}$ buz, kompresyon bandajı, elevasyon 
ve istirahatin ardından 24 saat sonra yapılan muayenede eklem hareket açıklığı, meniskal ve ligaman testlerinin normal olduğu gözlenmekle birlikte; fibula başında ödem ve palpasyonda lokal ağrı, hiperekstansiyona zorlamakla diz lateraline yayılan ağrı ve perküsyon ile tinel bulgusu saptandı. Ayrıca sağ diz ile kıyaslanınca sol diz fibula başının mobilitesinde artış ve mobilite testi sırasında ağrı olduğu gözlendi. $\mathrm{Bu}$ nedenle sporcunun sırasıyla bilateral iki yönlü diz grafisi, EMG, bilgisayarlı tomografi (BT) ve manyetik rezonans görüntüleme (MRG) tetkikleri yaptırıldı. EMG sonucunun normal çıkması ile, yüzeyel peroneal sinir yaralanması ekarte edildi. Görüntüleme tetkikleri sonucunda ise sol fibula başının sağa kıyasla posterolaterale deviye olduğu, ancak disloke olmadığı (Șekil 1), proksimal tibiofibular eklem ilișkisinin bozulduğu,

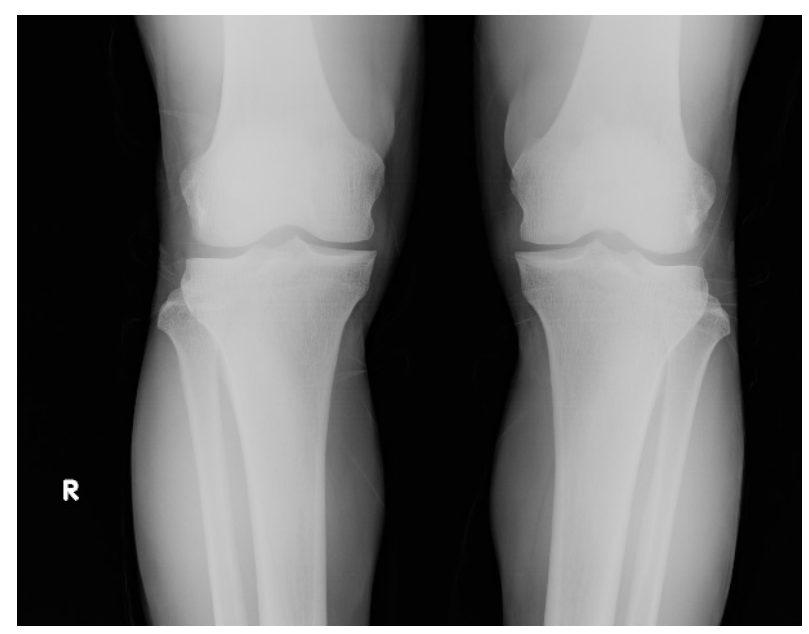

Şekil 1. Sol fibula başının non-disloke posterolateral deviasyonu

Üçüncü gün sonrası ağrı eşiğinde $5 \mathrm{dk}$ fibula bașı mobilizasyonu, $15 \mathrm{dk}$ hamstring-gastroknemius detonizasyonu, $7 \mathrm{dk} \% 80$ kesikli $1.5 \mathrm{~W} / \mathrm{cm}^{2}$ ultrason tedavisi, $15 \mathrm{dk}$ kısa dalga tedavisi ve üç set 10 tekrar eklem hareket açıklı̆̆l egzersizleri tedavi programına eklendi. Yaralanma sonrası altıncı gün $7 \mathrm{dk} \% 100 \quad 1.5 \mathrm{~W} / \mathrm{cm}^{2}$ ultrason tedavisine, $10 \mathrm{dk}$ bisiklet ve düşük dirençli egzersiz lastiği ile ayak bileğine dört yön üç set 15 tekrar kuvvetlendirme çalışmalarına başlandı. Dokuzuncu gün 2x10 dk düşük tempo düz koșu ile saha egzersizlerine geçilmiş oldu, ayrıca alt interosseöz membranda intensite değişiklikleri olduğu (Şekil-2), fibula başı ve komşuluğundaki tibia lateral plato düzeyinde medüller kemikte ödem rapor edildi. Sporcuya, spor hekimliği ve ortopedi uzman hekimleri fizik muayeneleri ve radyolojik görüntüleme tetkikleri sonucunda "Proksimal tibiofibular eklem sindesmoz sprain evre-2" tanısı konuldu. Takım antrenmanlarına geri dönüşü için iyileşme süresi 4-6 hafta öngörülerek tedavisi programlandı ve sporcuya bu süre zarfında balenli diz breysi kullandırıldı. Kulüp sağlık ekibi tarafından yürütülen fizik tedavi ve rehabilitasyon sürecinin ilk üç günü boyunca akut tedavi olarak; $25 \mathrm{dk}$ transkutanöz elektriksel sinir stimülasyonu (TENS), $20 \mathrm{dk}$ pnömatik kompresyon cihazı, $7 \mathrm{dk} \% 50$ kesikli $1.4 \mathrm{~W} / \mathrm{cm}^{2}$ ultrason tedavisi, $10 \mathrm{dk}$ yüzeysel masaj ve $15 \mathrm{dk}$ buz uyguland.

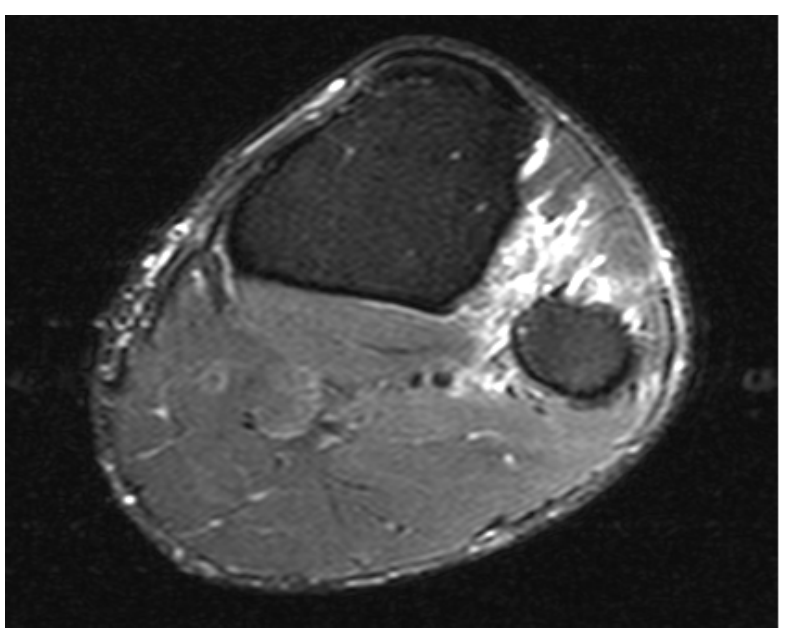

Şekil 2. Proksimal tibuofibular eklem ilişki bozukluğu, interosseöz membranda intensite değişikliği

ekstremite genel kuvvet ve statik denge çalışmaları da başlatıldı. Devam eden süreçte günden güne koşu temposu ve kuvvet çalışmaları

direnci arttırıldı. Rehabilitasyonun son döneminde propriyoseptif çalışmalar egzersiz programına eklendi. Yaralanma sonrası 30. gün yapılan futbola özgü saha içi, ani yön değiștirmeli sprint, sıçrama, top sürme, şut atma testlerinde herhangi bir sorun ile karşılaşılmamasının ardından, sporcunun fibula başını anteromediale doğru stabilize edecek şekilde koruyucu teypleme 
yapılarak takımla birlikte çalışmalara katılmasına onay verildi.

Yaralanmanın hemen sonrasında çekilen düz grafilerde gözlenen posterolateral deviasyon bulgusunun, tedavi ve rehabilitasyon süreci sonrası dramatik olarak gerilediği görülmektedir (Şekil 3).

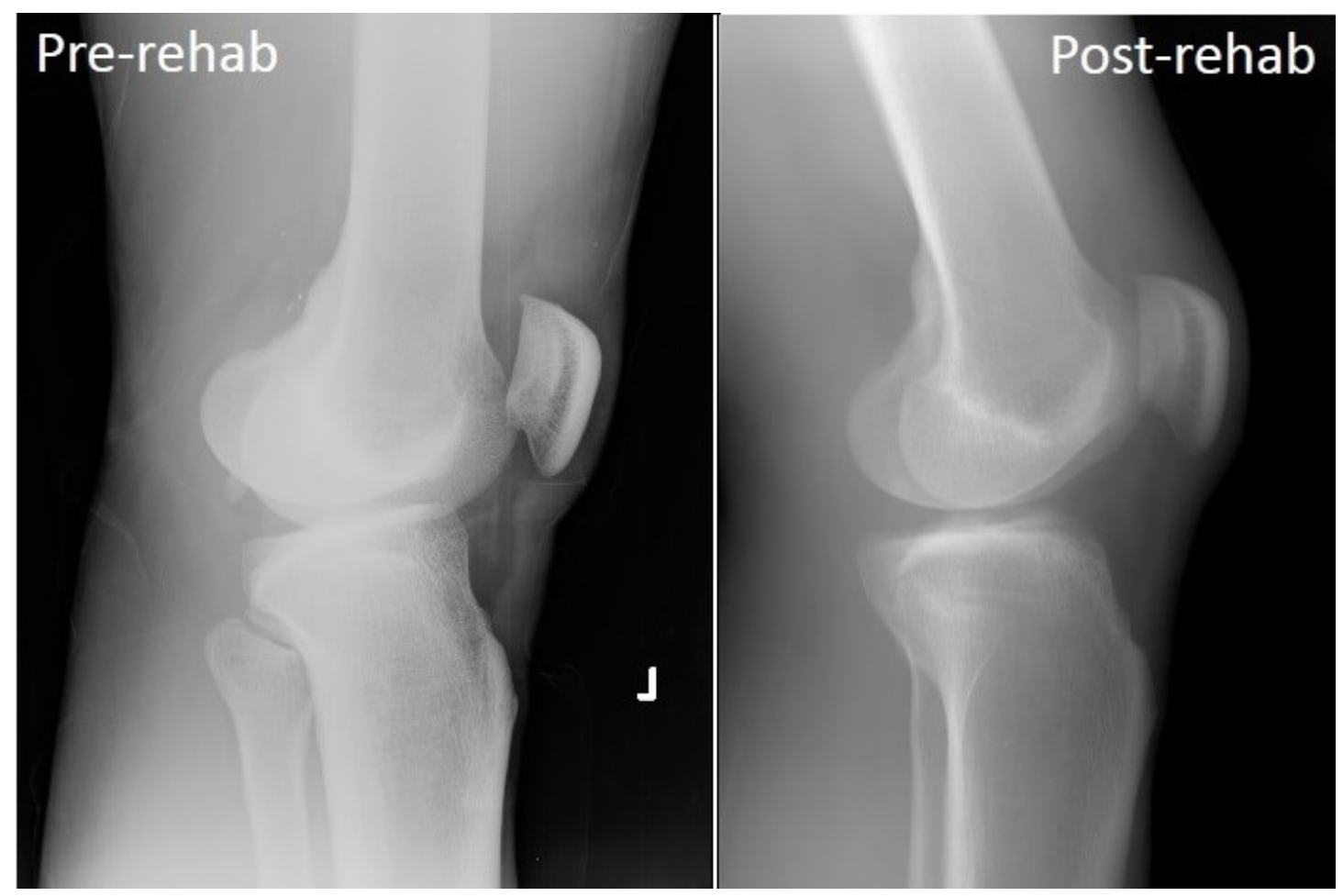

Şekil 3. Tedavi sonucu posterolateral deviasyon bulgusunun gerilemesi

Ayrıca, proksimal sindesmoz yaralanmasının ardından sporcu kulüp bünyesinde görev yaptı̆̆ bir buçuk futbol sezonu boyunca sağllk ekibi tarafından izlendi ve aynı bölgeden herhangi bir şikayeti olmadığı gözlendi.

\section{TARTIȘMA}

Proksimal tibiofibular sindesmoz yaralanması oldukça seyrek görülen bir diz eklemi patolojisi olup, dislokasyon olmaksızın sadece sindesmoz hasarı ise daha da nadirdir. Klasik ortopedi ve spor hekimliği ders kitaplarında PTF eklem yaralanmalarını açıklayacak spesifik klinik test ve radyolojik belirtilere ilişkin yeterli bilgi yoktur. Dolayısıyla, bu yaralanmaya tanı koymak oldukça zordur ve bu nedenle tedavi süreci gecikebilir. $\mathrm{Bu}$ gecikme profesyonel sporcularda süreci daha da karmaşık hale getirebilir. Tedavi edilmediği takdirde, hasta kronik ağrı duyar, yürüyüșü ve profesyonel sporcuysa koșması anormal hale gelir ve sonuç olarak performansı düşer (5).

$\mathrm{Bu}$ problemin seyrek görülmesi nedeniyle, tanı koyarken çok dikkatli olmak gerekmektedir (6). Tek başına fizik muayene veya radyografi ile sonuca varmak mümkün olmazken, tanı ancak ikisinin kombinasyonuyla konulabilmektedir. $\mathrm{Bu}$ nedenle acil servislere başvuran hastalarda veya profesyonel sporcularda bu lezyonlar tanınmayabilmekte, bunun sonucunda da yanlış tedavilerle zaman kaybedilmekte ve bu da işgücü kayıplarına yol açabilmektedir.

Ayrica bu yaralanmalarda peroneal sinir etrafinda da ödem ve enflamasyon gelişebilmekte ve bu da nöropraksiye yol açabilmektedir. Peroneal sinirde nöropraksi gelişmesi durumunda da tedavi 
süreci farklı işleyecektir. $\mathrm{Bu}$ nedenle tanıya yönelik rutin olarak EMG yapılmasının yararlı olacağı düşüncesindeyiz.

Literatürde PTFE yaralanmaları incelendiğinde, dislokasyon olmaksızın sindesmoz yaralanması bildiren çok az sayıda olgu olduğu görülmektedir. Bu duruma uyan, Solger ve ark.nın (7) sunduğu olguda hem distal, hem proksimal sindesmoz yaralanması saptanmıștır. Olgumuzda ise onların sunduğu olgudan farklı olarak izole proksimal tibiofibular sindesmoz yaralanması söz konusudur.

\section{SONUÇ}

Özet olarak, bu olguda seyrek görülen ve özellikle tanı aşamasında zorluklarla karşılaşılan "proksimal tibiofibular sindezmoz yaralanması" sunulmaktadır. Bu vakalar, özellikle spor hekimleri ve spor travmatolojisi ile ilgilenen ortopedistler açısından, belki de izlenen eğitim sürecindeki "fibulanın yük taşımadığı" şeklindeki nosyona bağlı olarak, tanınması zor vakalar olup tedaviyi de yanlış yönlendirebilmektedir (8). Bu nedenle, proksimal tibiofibular eklem ve sindesmoz yaralanmaları hakkında daha detaylı ve daha geniş serilerle yapılacak çalışmalar hekimlerin bilgi ve deneyim eksikliklerini gidermelerine yardımcı olacak, ayrıca tedavide izlenecek yolun belirlenmesini ve daha kısa sürede, daha etkin yanıt alınmasını sağlayacaktır.

Tüm bu bilgiler ıșığında açılkça ortadadır ki, PTFE yaralanmaları ve türevlerine literatürde ve klasik ders kitaplarında daha fazla yer ayrılmalıdır. Bunun gerçekleştirilmesi, proksimal tibiofibular sindesmoz yaralanmasinın tanınmasını ve dolayısıyla tedavisini daha da kolaylaştıracak olup, yanlıș tanı ve tedavi sonucu oluşabilecek iş gücü kaybı ve gereksiz harcamalardan kurtaracaktır.

\section{KAYNAKLAR}

1. Aladin A, Lam KS, Szypryt EP. The importance of early diagnosis in the management of proximal tibiofibular dislocation: a 9 and 5-year follow-up of a bilateral case. Knee. 2002;9(3):233-6.

2. Ellis C. A case of isolated proximal tibiofibular joint dislocation while snowboarding. Emerg Med J. 2003; 20(6):563-4.

3. Van Seymortier P, Ryckaert A, Verdonk P, et al. Traumatic proximal tibiofibular dislocation. Am J Sports Med. 2008; 36(4):793-8.

4. Chiu C, Sheele JM. Isolated proximal tibiofibular dislocation during soccer. Case Rep Emerg Med. 2015;657581.

5. Crothers OD, Johnson JT. Isolated acute dislocation of the proximal tibiofibular joint. Case report J Bone Joint Surg Am. 1973;55(1):181-3.

6. Iosifidis MI, Giannoulis I, Tsarouhas A, et al. Isolated acute dislocation of the proximal tibiofibular joint. Orthopedics. 2008;31(6):605.

7. Solger EA, Schweim JJ, Tripp PM. Proximal and distal tibofibular syndesmosis injury in a collegiate football athlete. Int J Athl Ther Train. 2013;18(3):24-7.

8. Sarma A, Borgohain B, Saikia B. Proximal tibiofibular joint: Rendezvous with a forgotten articulation. Indian J Orthop. 2015;49(5):489-95. 